\title{
NEURAXIAL ANAESTHESIA AFTER SPINAL BONE TUBERCULOSIS (SBT): CASE REVIEW
}

Biosca E., Broseta A., Moreno J., Errando C., Montagud A., De Andrés J. Hospital General Universitario de Valencia, Dept of Anaesthesiology \& Intensive Care, VALENCIA, Spain

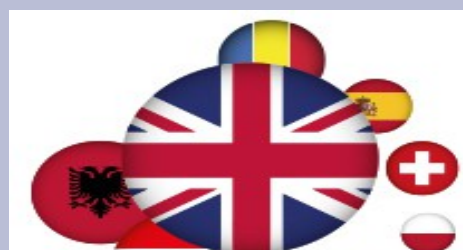

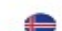

\section{Euroanaesthesia}

CONSORCIO
HOSPITAL GENERAL
UNIVERSITARIO
DE VALENCIA

\section{INTRODUCTION}

Tuberculosis (TB) affects the spine in $1 \%$ (the so called Pott's disease). Both the Optimal treatment duration and bone healing criteria remain controversial.

Thus, neuroaxial anaesthesia techniques in patients with treated Pott's disease are conflicting.

\section{CASE REPORT}

A 25-year-old female from Pakistan, 37 weeks pregnant, requested epidural analgesia during labour.

She suffered tuberculous spondylodiscitis (T11-L1, 9x4 cm abscess) the year before. She received quadruple therapy against TB for 12 months and the abscess was percutaneously evacuated, afterwards she remained asymptomatic.

At six months of treatment, a MRI was performed showing image improvement. However, persistent infection could not be excluded because of persistence of granulation tissue (figure)

By agreement with obstetricians and midwives, epidural analgesia was avoided and iv analgesia provided (meperidine) The labour occurred without incidences.

\section{DISCUSSION}

We have'nt found references on the use of neuraxial anaesthesia in patients with treated osseous TB, probably because there is no consensus on the optimal duration of the treatment, and on the radiological criteria of complete healing. The WHO and the American and Canadian Thoracic Societies recommend a fixed duration of treatment (between 6 and 12 months). In spite of this, recent reports suggest that the completion may be supported by MRI criteria as, in some asymptomatic patients, lesions remained beyond the 12 months of treatment.

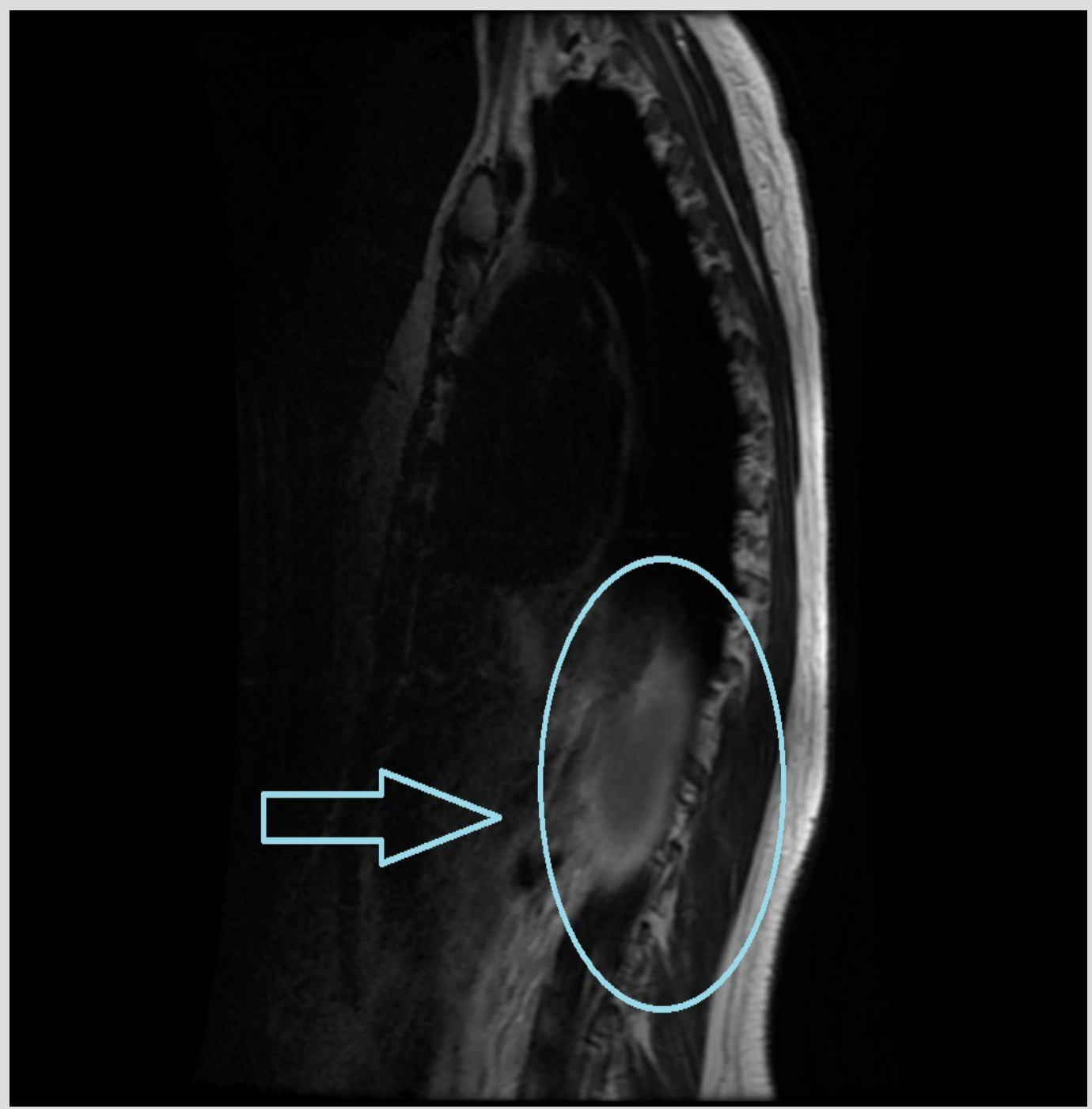

\section{CONCLUSIONS}

There is not enough evidence to assume that the end of the treatment reflects the safety timeframe needed to perform a neuraxial anaesthetic technique in patients with spine TB. It seems reasonable to verify the absence of lesion on MRI before performing these procedures. 